\title{
Microplastic contamination in soil environment - a review
}

\author{
Young-Nam Kim¹, Jung-Hwan Yoon ${ }^{1}$, Kye-Hoon Kim ${ }^{1 *}$ \\ ${ }^{1}$ Department of Environmental Horticulture, The University of Seoul, Seoul 02504, Republic of Korea \\ * Professor Kye-Hoon Kim, johnkim@uos.ac.kr, ORCID iD: https://orcid.org/0000-0002-9745-6551 (YN KIM), https://orcid.org/0000-0001-8009-7807 \\ (JH YOON), https://orcid.org/0000-0002-4891-3322 (KH KIM)
}

Received: 04.08.2020

Accepted: 14.12.2020

Associated editor: Ł. Uzarowicz

\section{Keywords}

\section{Microplastics}

Soil pollution

Soil biogeochemistry

Soil organisms

Terrestrial ecosystem

\begin{abstract}
Plastic is an indispensable material essential for modern human life. With highly increasing demand for plastic use, however, environmental contamination by plastic litters has become an emerging issue. Globally, large quantity of used plastics is landfilled or emitted directly to the aquatic and terrestrial environments, albeit a part of the plastics is recycled or incinerated as energy source. In particular, microplastic debris that are smaller than $5 \mathrm{~mm}$ are considered to be emerging contaminants of global concern. In the past decade, however, most of the researches on impacts of microplastic contamination have been focused on the marine ecosystem, whereas very limited ones on the terrestrial ecosystem. Soil can be considered as a major sink and a carrier of microplastic contaminants to the aquatic environment. Most sources of microplastics in the soil environment are entered via a variety of routes and subsequent fragmented and spread to the surrounding environments, vertically and horizontally. In addition, there are negative impacts on soil biota, which in turn would cause concerns of human health by affecting the food web. Here, we provide an overview of characteristics, research trend, analytical methods, migration and degradation processes, effects on soil biogeochemistry, and interaction with soil organisms of microplastics suggesting the importance of ongoing research impacts of microplastics on the terrestrial ecosystem.
\end{abstract}

\section{Introduction}

Plastic is a greatly versatile material and is beneficial to manufacture due to convenience, economics, hygiene, high durability, and ease of processing, affecting on a wide range of industry and life (Andrady and Neal, 2009). Because of such benefits, the plastics have been ideally used for a wide range of consumers and industrial applications such as packaging, building, healthcare materials, auto parts, household goods, and agricultural materials. Plastics have been produced from different sources including fossil origin (crude oil, natural gas, etc.) or renewable materials (sugar cane, starch, vegetable oils, etc.). Depending on the intended use, each plastic is designed with appropriate characteristics for ideal application.

In general, plastics made of synthetic organic polymers are largely divided into two types such as thermoplastics and thermoset resins (Geyer, 2020). The thermoplastics have a reversible trait and can be melted when heated and hardened when cooled. Thereby it is easy to reshape as new materials by reheating and cooling. They include polyethylene (PE), polypropylene (PP), polyvinyl-chloride (PVC), polyethylene terephthalate (PET), polystyrene (PS), expanded polystyrene (EPS), acrylonitrile butadiene styrene (ABS), styrene acrylonitrile (SAN), polyamides (PA), polycarbonate (PC), poly methyl methacrylate (PMMA), thermoplastic elastomers (TPE) etc. On the other hand, the thermosets have an irreversible trait that cannot be re-melted nor reshaped by heating due to a chemical change when heated initially. The examples of thermosets include polyurethane (PUR), unsaturated polyesters, epoxy resin, silicone, phenol-formaldehyde (PF), acrylic resin etc.

Plastics based on synthetic resins were first made in 1907, and the plastics industry has developed with the development of highly functional plastics (Thompson et al., 2009). With increase in demands of plastic use, the global production of plastics has skyrocketed in the past decades. The plastic production in 1950 was about 2 million tonnes (Mt) and currently, reached to $359 \mathrm{Mt}$ in 2018, with an annual growth rate of 8.4\% (Geyer et al., 2017; Plastics Europe, 2019). Of the plastic production in 2018, 51\% are produced in Asia (Plastic Europe, 2019). In particular, China has been the world's largest manufacturer and consumer since 2010, accounting for a third of the global production (Jiang et al., 2020). The Republic of Korea (ROK) produced 21 Mt of the plastics, accounting for about $6.2 \%$ of the world's total plastics production (Statistics Korea, 2019). Also, Europe and North America contribute to 17 and 18\% of the global total production, respectively (Plastic Europe, 2019). It can 
be estimated that total cumulative primary plastics production is about 9.6 billion tonnes between 1950 and 2018 (Plastics Europe, 2019; Geyer, 2020) and will reach up to 34 billion tonnes by 2050 (Geyer, 2020).

With a rapid economic growth, the plastic is closely associated to our lives. However, plastic-production boom with excess use causes the global environmental concern as other anthropogenic pollutants such as heavy metals. In particular, the continuous increase in the amount of plastic waste proportionate to the amount of plastics produced, which can cause the serious plastic pollution in the future. As of 2015, 60-99 Mt of mismanaged plastic waste was globally generated as estimated by Lebreton and Andrady (2019). In ROK alone, the amount of generated plastic waste was about 7.1 Mt in 2016, which increased by $7.2 \%$ in 5 years since 2012 (Kim et al., 2018). Such wasted plastic materials are persistent and recyclable, but about $80 \%$ of global plastic wastes is piled in landfills (Geyer et al., 2017; Ng et al., 2018). The stacked plastic debris on lands can be fragmented by physical, chemical, and biological degradation, contributing to high abundance of smaller plastic particles in soil.

Microplastics (MPs) are small-size plastic fragments with smaller than $5 \mathrm{~mm}$ and were recently detected in a wide range of environments such as soil, freshwater, ocean, and organisms (He et al., 2018). Extreme increase of microplastic contamination is a growing environmental concern around the world. Studies focusing on MPs contamination in the ocean have been mainly performed due to a threat to a wide range of aquatic organisms and subsequent food security, whilst lacking studies of its impacts on the soil environment. Considering the fact that most of the microplastic litters are accumulated in fresh water and marine ecosystems following passing through the terrestrial environment, soil would be the origin and dominant sink of microplastics (Guo et al., 2020). Therefore, it can be expected, regardless of the pathway processes, that the presence of microplastics directly and indirectly influences terrestrial organisms (e.g., microorganisms, invertebrates, animals) as well as soil characteristics, affecting soil function and ecosystem.

Up to now, review papers related to microplastic in soils are quite limited although the number of soil scientists and ecologists who have a strong interest on that are significantly increasing in recent years (Horton et al., 2017; He et al., 2018; Wang et al., 2020). In the present review, we provide an overview of characteristics, research trend, analytical methods, and effects on soil biogeochemistry of MPs, and suggest the importance of continuous research on impacts of MPs on soil ecosystem.

\section{Microplastics in soil}

\subsection{Definition, classification and sources}

The presence of small plastic debris in the ocean was first highlighted in the 1970s (Carpenter and Smith, 1972), and such tiny plastic fragments, granules, and fibers were collectively referred to as 'microplastics'. In recent years, microplastics (MPs) are highly considered as one of the newly emerging pollutants, causing the potential to infest biota in the marine and terrestrial ecosystems. In general, MPs are defined as fragmented or weathered plastic debris, which are smaller than $5 \mathrm{~mm}$, by the National Oceanic and Atmospheric Administration (NOAA). In the early stage of research on MPs, however, a wide range of size of plastic debris, varying from study to study, had been applied to classify without a scientific standard (Cole et al., 2011): e.g. with diameters of $<10 \mathrm{~mm}$; $<5 \mathrm{~mm} ; 2-6 \mathrm{~mm}$; $<2 \mathrm{~mm}$; and $<1 \mathrm{~mm}$. This discrepancies in the size category caused difficulties when comparing data referring to MPs. Currently, plastics are categorized according to the size (Fig. 1): macroplastics (MAPs; > $25 \mathrm{~mm}$ ), mesoplastics (MEPs; 5-25 mm), large microplastics (LMPs; $1-5 \mathrm{~mm}$ ), small microplastics (SMPs; $1 \mu \mathrm{m}-1$ $\mathrm{mm}$ ) and nanoplastics (NPs; < $1 \mu \mathrm{m}$ ) (GESAMP, 2016; Hanvey et al., 2017).

Microplastics can be classified into primary and secondary MPs according to the manufacturing purpose and fragmentation (Browne et al., 2011; Masura et al., 2015). Primary MPs are purposefully produced for specific items which are smaller than $5 \mathrm{~mm}$. They include industrial scrubbers, plastic powders, micro-beads in household goods such as toothpaste and face wash, cosmetics, and fabric softeners etc. (GESAMP, 2016). Once these MPs enter into wastewater, it is usually difficult to remove by sewage disposal technologies (Guo et al., 2020). Secondary MPs originate from larger plastic particles by progressive fragmentation or weathering. Once used plastic items such as tires, paint, vinyl, disposables, or electronics are emitted into the surroundings, multiple environmental conditions like wind, temperature, and UV light etc. lead to decomposition of large plastics and subsequent create these MPs (Andrady, 2011; Kim et al., 2017). In the

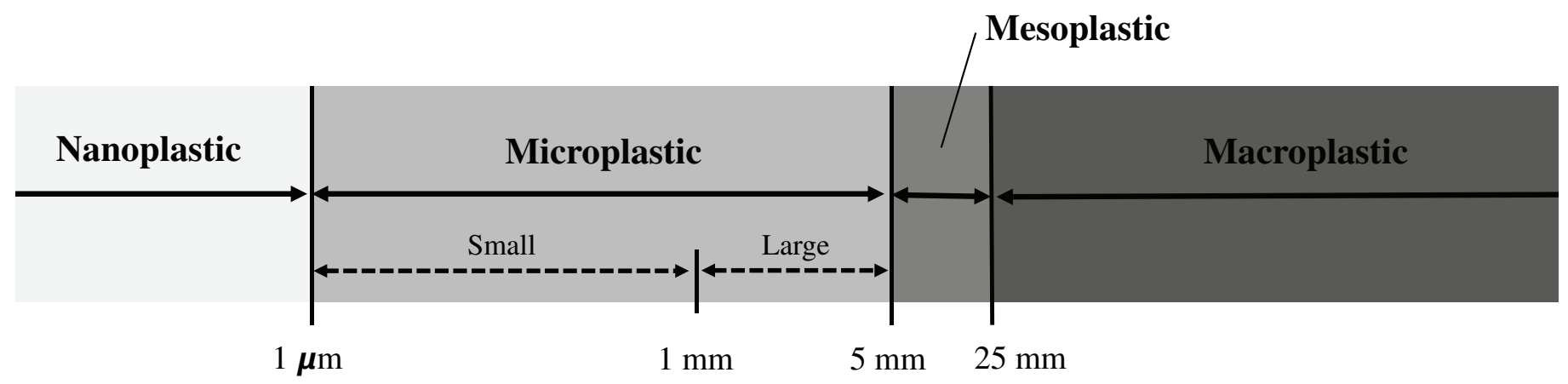

Fig. 1. Classification of particulate plastics based on size (GESAMP 2016; Hanvey et al., 2017) 
soil environment, relatively more naturally fragmented secondary MPs exist than primary MPs (Horton et al., 2018; Townsend et al., 2019).

Sources of MPs to the terrestrial environment originate mostly from anthropogenic inputs, including landfills, soil amendments, irrigation, road runoff, and atmospheric deposition (Bläsing and Amelung, 2018). Such anthropogenic activities generate multiple sources of MPs, which unintentionally enter and accumulate in agricultural and urban soils. Application of organic wastes such as sewage sludge and compost as fertilizer is the main source of MPs in agricultural soil (He et al., 2018). As several studies reported MPs concentration in the organic fertilizers, compost and sewage sludge range from 14 to 1,200 particles $\mathrm{kg}^{-1}$ (Gajst, 2016; Bläsing and Amelung, 2018; Weithmann et al., 2018) and from 250 to 24,000 particles $\mathrm{kg}^{-1}$ (Mahon et al., 2017; Mintenig et al., 2017; Zhang et al., 2020), respectively. As such, the organic fertilizers can act as vehicles for MPs to enter into soils. Nizzetto et al. (2016) estimated that up to 0.43 and $0.03 \mathrm{Mt}$ of MPs are annually entered by application of sewage sludge into European and North American farmland soils, respectively. Additionally, plastic residues of mulching films and wastewater-irrigation for farming practices to improve crop yields have been significant sources of MPs in the soil (Bläsing and Amelung, 2018; Guo et al., 2020). In addition to agricultural sources, high diversity of sources contributes to MPs contamination in urban areas including tires of vehicles, industrial plastics, littering, wastewater effluent, and atmospheric dust (Grbić et al., 2020; Wright et al., 2020).

\subsection{Study trend in soil microplastics}

The first scientific report on MPs investigation was published in the early 1970s by Carpenter and Smith (1972) who found plastic pellets and fragments on the Sargasso Sea surface. Then, Carpenter et al. (1972) raised concerns of these harmful impacts on fish species. Following Carpenter's publications, there had been a growing interest in plastic litter and its impacts on the marine ecosystem, so that a large number of MPs studies have been reported after 1972 (Ryan, 2015). Thompson et al. (2004) first raised the issue of microplastic debris in the marine environment and according to the Web of Science, the number of microplastic-related papers published between 2010 and 2020 has been steadily increased (Fig. 2). However, albeit soil plays a mediating role for microplastic to accumulate and move to the water system, unlike the ocean, researches on MPs in soil began relatively too late. When surveying the trend of research papers on MPs over the past decade, there have been few studies related to the presence of MPs in soils (Fig. 3). Rillig (2012) first addressed that accumulation of MPs greatly affect the functions and biodiversity of the soil and subsequent many studies on distribution and investigation of MPs in soils of various regions are being actively conducted in recent 5 years (Fig. 2) in order to understand impact of MPs on the soil biogeochemistry and terrestrial ecosystem.

Among the countries of the world, China is the largest of plastic producers and consumers in the past decade and has predominantly conducted studies of soil microplastic contamination, followed by the United States, and European and Asian countries (Table 1). Considering most of plastic waste is primarily exposed to soil at first, it can be expected that there will be more microplastic litters in the soil than the ocean (Hurley and Nizzetto, 2018). Thus, the more presence of MPs in soil environment would degrade quality and health of soil as other toxic pollutants, contributing to negative impacts on food security as well as ecosystem. Hence, a lot of researches are needed to be implemented to uncover the unknown effects of MPs yet.

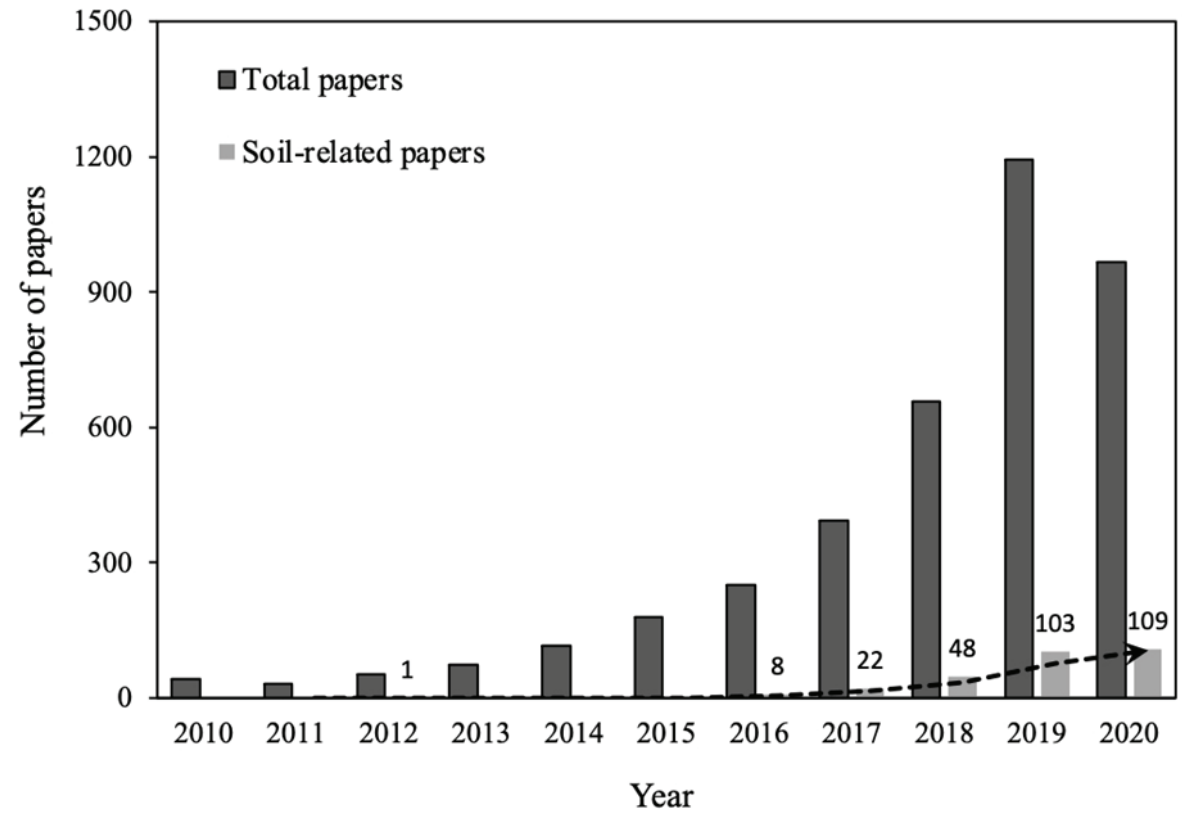

Fig. 2. Annual number of published papers related to microplastics, including microplastics in soil, from 2010 to 2020. Data are from the Web of Science through searching "microplastic" or "micro-plastic"

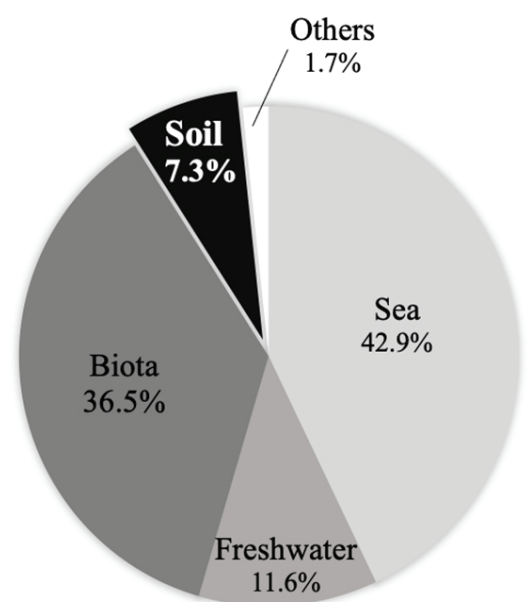

Fig. 3. Proportion of microplastics studies in sea, freshwater, biology, soil, and others between 2010 and 2020, by referring to the database of the Web of Science 
Table 1

The number of published papers on microplastics according to country during 2010-2020 (classifying papers about microplastics in Fig. 2 from Web of Science)

\begin{tabular}{llll}
\hline Ranking & Country & No. of papers & Share (\%) \\
\hline 1 & China & 872 & 22.0 \\
2 & USA & 574 & 14.5 \\
3 & UK & 427 & 10.8 \\
4 & Germany & 436 & 11.0 \\
5 & Italy & 306 & 7.7 \\
6 & Spain & 245 & 6.2 \\
7 & France & 239 & 6.0 \\
8 & Australia & 208 & 5.2 \\
9 & Netherlands & 179 & 4.5 \\
10 & Canada & 174 & 4.4 \\
12 & Republic of Korea & 125 & 3.2 \\
33 & Poland & 30 & 0.8 \\
\hline
\end{tabular}

\subsection{Analytical methods for soil microplastics}

In the past 5 years, the number of researches on microplastics in soil is extremely increasing, yet the analytical methods for MPs research varied among research groups (He et al., 2018). Most of the analytical procedures, from soil extraction to identification and quantification, used for MPs in soils are similar with those in water and sediments. Throughout the analysis for MPs in soil, proper soil sampling is the most important phase for MPs analysis (He et al., 2018). This is because the distribution and quantity of MPs can vary considerably with land use type and other anthropogenic legacies on each sampling site. Yet, difference in knowledge and views on microplastics in the terrestrial ecosystem still makes a difficulty to standardize the methods available for identification and quantification of MPs in soil.

In addition to non-standardized protocols, the accuracy in MPs measurement depends highly upon consistency and uniformity of the analytical procedure. Generally, the analytical procedure of soil microplastics includes drying, sieving, den- sity separation, extraction, organic matter (OM) digestion, and filtration (Bläsing and Amelung, 2018; Wang et al., 2020). Prior to separate microplastics from soil, the samples are air-dried and sieved with a $5 \mathrm{~mm}$ metal sieve, followed by density separation to remove the mineral fractions of soil with saturated salt solutions. Varying the density of plastic types requires the solutions with different densities (Table 2). Sodium chloride $(\mathrm{NaCl})$ has been widely used for separation but limited to plastics with density lower than $1.2 \mathrm{~g} / \mathrm{cm}^{3}$ (Thompson et al., 2004); e.g. PE (0.92-0.97 g/cm $)$, PP (0.85-0.94 g/ $\left./ \mathrm{cm}^{3}\right)$, and PS $(0.96-1.05$ $\left.\mathrm{g} / \mathrm{cm}^{3}\right)$. Alternatively, high-density solutions of $\mathrm{ZnCl}_{2}(1.5-1.7 \mathrm{~g} /$ $\mathrm{cm}^{3}$ ) or $\mathrm{NaI}\left(1.8 \mathrm{~g} / \mathrm{cm}^{3}\right)$ are suggested to be used for better separation of more diverse plastic types, including PVC (1.3-1.7 g/ $\mathrm{cm}^{3}$ ) and PET (1.4-1.6 g/ $\mathrm{cm}^{3}$ ), albeit both salts are costly (Imhof et al., 2012; Nuelle et al., 2014; Wang et al., 2020).

Separation of MPs in organic-rich soils by density is usually insufficient because the density of soil organic matter (SOM, $1.0-1.4 \mathrm{~g} / \mathrm{cm}^{3}$ ) is similar with several types of plastic including PET and nylon (Bläsing and Amelung, 2018). Soil contains various solids such as organic matter, minerals, and clay, which

Table 2

Solutions for extracting microplastics in soil through the density separation method

\begin{tabular}{lll}
\hline Polymer type & Extracting solution & Density \\
\hline Polyethylene (PE) & $\mathrm{NaCl}$ & $1.2 \mathrm{~g} / \mathrm{cm}^{3}$ \\
Polypropylene (PP) & & \\
Polystyrene (PS) & & \\
\hline Polyvinyl chloride (PVC) & $\begin{array}{l}\mathrm{ZnCl} \\
\text { or } \\
\text { Polyester (PET) }\end{array}$ & $\mathrm{NaI}$ \\
Polyamide (PA) & & $1.5-1.7 \mathrm{~g} / \mathrm{cm}^{3}$ \\
\hline
\end{tabular}


not only affect the soil characteristics but also act as habitats for soil biota. Soil organic matter can interact with minerals and also other impurities. In terms of the OM trait, thus, tiny plastic fragments can be embedded in SOM, leading to an extreme challenge for identification and quantification of MPs by interfering with reading the signals of Fourier transformed infrared (FT-IR) and Raman spectroscopy mainly used as identifiers (Bläsing and Amelung, 2018; He et al., 2018). Hence, SOM removal from the samples is needed. For water, sediment, and biological samples, various chemicals such as acid $\left(\mathrm{HNO}_{3}\right)$, alkaline ( $\mathrm{NaOH}, \mathrm{KOH})$, oxidizing agent $\left(\mathrm{H}_{2} \mathrm{O}_{2}\right)$, enzymes (cellulase, lipase, proteinase, amylase, and chitinase), or the mixtures of those mentioned above were utilized (Hurely et al., 2018; Wang et al., 2020). However, several studies reported that acid, alkaline, and $\mathrm{H}_{2} \mathrm{O}_{2}$ treatments cause damage or degradation of the plastic particles during the digestion process. Recently, Fenton's reagent (a solution of $\mathrm{H}_{2} \mathrm{O}_{2}$ with ferrous iron) in conjunction with density separation method is suggested as an optimal digestion protocol for the OM removal efficiency to address this limitation (He et al., 2018; Hurely et al., 2018).

After extraction procedure, microplastics isolated from soil samples can be identified and quantified by several methods. First, visual sorting and use of spectroscopic technique are the most essential step for MPs identification, representing the surface texture and characteristics of suspected plastic particles. Through the visual identification, morphological characteristics of MPs such as size, shape, and color can be classified (Shim et al., 2017); however, this is often inaccurate (e.g., Eriksen et al., 2013; Lenz et al., 2015). Thus, it is important to combine the visual identification with other physical or chemical technologies (He et al., 2018). For chemical identification of MPs, FT-IR and Raman spectroscopies have been widely used and which can detect very small particles, down to $10 \mu \mathrm{m}$ and less than $1 \mu \mathrm{m}$, respectively (Wang et al., 2020). Currently, both spectroscopies are the key techniques, but greatly relying on removal effectiveness of OM from soil samples (Bläsing and Amelung, 2018). Additionally, some thermoanalytical techniques such as pyrolysis and thermal extraction desorption-gas chromatography mass spectrometry (pyr-GC-MS and TED-GC-MS) and thermogravimetric analysis mass spectrometry (TGA-MS) have been developed for efficiency in identifying and quantifying MPs (Dumichen et al., 2017; David et al., 2018; Kappler et al., 2018). However, they cannot analyze the number and morphological characteristics of MPs. Recently, new techniques of macroscopic dimensioned near-infrared (NIR) process-spectroscopy in combination with chemometrics (visible NIR spectroscopy) and hyperspectral imaging have been applied, which are capable of economic and faster analysis than other techniques (Corradini et al., 2019; Shan et al., 2019).

\subsection{Migration of microplastics in soil}

Microplastic debris have now been detected in a wide range of terrestrial ecosystems, such as farmlands (Steinmetz et al., 2016; Choi et al., 2020), urban/industrial areas (Sommer et al., 2018; Choi, 2020), and forests as undisturbed areas (Klein and Fisher, 2019). Generally, higher abundance of MPs has found in shallow soils than in deep soils (Liu et al., 2018), with variance at different soil depths. Once MPs are deposited at the soil surface via a variety of entry routes, they migrate into deeper soil or disperse to the surrounding environment (Guo et al., 2020). Accordingly, soil is not only a major sink of MPs, but also a carrier of MPs to groundwater and the ocean environment (Qi et al., 2020). Transport of soil MPs into the aquatic ecosystem is mainly associated with surface runoff, erosion, etc. (Steinmetz et al., 2016; Bläsing and Amelung, 2018); however, knowledge of the migration of MPs in the soil profile is quite limited.

There are several possible mechanisms related to the transport of MPs into belowground: bioturbation by plant roots and soil fauna (Rillig et al., 2017), agricultural practices such as tillage and crop harvest (Liu et al., 2018; Zhang et al., 2018), water infiltration (Luo et al., 2018), and wet-dry circles causing soil cracking (O'Connor et al., 2019). These factors could facilitate microplastics downward movement of MPs. Among soil animals, earthworm, especially anecic species, is considered as a transporter or diffuser of soil MPs via burrowing, ingestion, and casting (Cao et al., 2017; Rillig et al., 2017). Also, other soil biota including mites, collembola, and mosquito larvae have been reported to disperse and redistribute MPs in soils by burrowing and feeding activities (Rillig, 2012; Maaß et al., 2017; Al-Jaibachi et al., 2019). Additionally, the characteristics of MPs such as shape, type, and surface condition are important for MPs to migrate in soils (Guo et al., 2020; Qi et al., 2020). For example, de Souza Machado et al. (2018) found that microbeads and microfibers have different interaction with soil aggregation, which greatly influence the mobility of MPs in soils.

\subsection{Impacts of microplastics on soil biogeochemistry}

Once MPs are deposited in top soils, the fragmentation or weathering of MPs occur by solar UV radiation as well as elevated oxygen availability and temperature (Horton et al., 2017; He et al., 2018). These fragmented MPs can migrate vertically through soil profile and horizontally along the surface of soils, leading to spreads of plastic contamination over a wide range including deep soil, groundwater, and the aquatic ecosystems. Indeed, intensive anthropogenic activities can stimulate the dispersion of microplastic pollutants, which may influence the soil biogeochemical properties and biodiversity (Rillig, 2012; He et al., 2018). However, few studies have been conducted and reviewed for possibility of changes in the biogeochemical status and biota community of soil by contamination of MPs as well as its potential risks to human health so far (e.g., Horton et al., 2017; Guo et al., 2020).

Incorporation of MPs with the soil matrix can alter soil structure (Guo et al., 2020). Microplastics migrated into soil profile could transmute physical properties of soil, in particular porosity, thereby influencing water cycling and soil aggregation that are important parameters for soil function (Wang et al., 2020). de Souza Machado et al. (2019) revealed that inputs of MPs altered several physical parameters of the soil: decreases in bulk density (by PEHD, PES, PET, PP, and PS) and water stable aggregates (by PA, PES, and PS) and increase in water availability with all MPs. On the other hand, water evaporation 
increased with polyethylene films (Wan et al., 2018); this is because a channel has been created for water movement by the presence of MPs. The results of earlier studies showed significant impact of MPs present on the soil structure, but varying with type of MPs, aggregate size fraction, and plant roots that contribute to water dynamics and related microbial activity in belowground (de Souza Machado et al., 2019).

Plastic materials contain a high content of carbon (Rillig, 2018), which is very recalcitrant to decompose. Since MPs are fragmented over the years can be eventually degraded, the presence of MPs in soil would become a potential C source for microbiota (Rillig et al., 2019). Additionally, de Souza Machado et al. (2019) suggested that some plastic polymers have nutrient elements that may affect biogeochemical properties of soil: for example, nitrogen $(\mathrm{N})$ for polyacrylonitrile and polyaramide; and fluor (F) for polytetrafluoroethylene. Although such nourishable role of MPs in the soils should be further proved, it is likely that some of MPs could alter soil biogeochemical cycle through leaching process. Also, due to microplastic's hydrophobicity and large surface area, a variety of toxic chemicals such as heavy metals (Hodson et al., 2017; Rodríguez-Seijo et al., 2019; Wang et al., 2019a), hydrophobic organic compounds (Ramos et al., 2015; Yang et al., 2019), and antibiotics (Sun et al., 2018) can be adsorbed on the surface of MPs. Microplastics that have already adsorbed these contaminants can affect negatively the soil ecosystem if exposed to the surroundings via leaching. Hence, this may aggravate soil contamination and increase a risk to the surrounding organisms and humans (Guo et al., 2020). Reversely, newly introduced MPs into contaminated soils could be a good adsorbent that can reduce the mobility and bioavailability of the contaminants. However, the process of both sorption and desorption varies greatly among polymers as well as by interaction of MPs and soil media (Wang et al., 2019a). Therefore, more studies are needed to understand the relationship between MPs and contaminants and their impact on the terrestrial ecosystem.

\subsection{Interaction of microplastics with soil organisms}

Recently, a large number of researchers are interested in microplastic contamination, focusing on the aquatic ecosystem, rather than the terrestrial ecosystem. Microplastics in soil can be ingested by soil organisms mostly through their feeding activity. In most cases, MPs are unconsciously ingested by the organisms that are unable to digest the plastic particles (Wang et al., 2019b). Based on researches about the marine organisms (e.g., da Costa et al., 2016; Lönnstedt and Eklöv, 2016; Setälä et al., 2016; Lahive et al., 2019), the intake of MPs may cause growth loss, reproduction reduction, and mortality of terrestrial organisms due to nutritional imbalance, organ damage, and disorders of immune responses and metabolisms. In addition, capacity of MPs to adsorb inorganic and organic pollutants may facilitate the pathway of the pollutants into the organisms through degradation process (Hodson et al., 2017; Wang et al., 2019b). Moreover, the bioaccumulation and subsequent trophic transfer of MPs via the terrestrial food chain system may eventually adversely affect the health of humans as the highest predator (Guo et al., 2020). As an estimation by Cox et al. (2019), the amount of microplastic intake via air, water, and food consumption, including seafoods, salt, sugar, poultry etc., is 39,000-52,000 particles per person per year.

In soil ecosystem, microbes account for a significant portion of the whole terrestrial organisms, but knowledge of the impact of MPs on them is quite limited. Nevertheless, we can easily expect that alteration of soil structure and function by the presence of MPs could influence composition and diversity of microbial community, in particular, of rhizosphere microbes such as N-fixers, mycorrhizal fungi, and pathogens (Rillig et al., 2019). Many studies also reported that the presence of MPs altered activities of soil microbial enzymes such as dehydrogenase, leucine-aminopeptidase, alkaline-phosphatase, $\beta$-glucosidase, cellobiohydrolase, and fluorescein diacetate hydrolase. They vary with the traits and concentrations of MPs, enzyme types, and presence of plants (Awet et al., 2018; de Souza Machado et al., 2019). On the other hand, MPs can serve as novel microbial habitats in soil (Wang et al., 2019b), so are called as 'plastisphere' (Zettler et al., 2013). Hence, biodegradation of MPs can be promoted by some bacteria and fungi that inhabit in this space (Shah et al., 2008). However, research into the impact on the soil environment is needed in the future since some toxic pollutants contained or adsorbed by MPs can be released into the surroundings during the microbial biodegradation process.

\section{Summary}

Recently, MPs are ubiquitous contaminants of globally emerging concerns in their toxicity and other negative effects on both aquatic and terrestrial ecosystem. However, there are very limited studies about MPs contamination in the soil environment despite the fact that soil acts as a primary reservoir and a carrier of MPs transferring to other environments. Microplastics enter soil ecosystem mostly through landfills, soil amendments, agricultural films, tire abrasion, and atmospheric deposition. Microplastics amended with soil can alter soil structure and interact with other soil factors, significantly influencing soil function and organism abundance. Soil scientists suggest some positive aspects of MPs presence in soil such as increases in C pool, fertility, and microbial habitats; however, it should be more focused on hazardous substances derived from the plastics that directly or unintentionally deteriorate the quality and health of soil, which in turn will affect human health via the food chain system eventually. However, there is a significant lack of studies on the effects of MPs in soil ecosystems and human health so far. Moreover, the MPs influence can depend considerably on their type, size, shape, and purpose of use, which requires more intensive researches on MPs contamination in soil. Therefore, we need to improve our insights of migration and degradation processes of diverse types of MPs as well as their interactions with a variety of soil parameters including soil organisms in order to prevent wide spread of MPs contamination and decrease the risks to the terrestrial ecosystem. 


\section{References}

Al-Jaibachi, R., Cuthbert, R.N., Callaghan, A., 2019. Examining effects of ontogenic microplastic transference on Culex mosquito mortality and adult weight. Science of the Total Environment 651, 871-876. https://doi.org/10.1016/j.scitotenv.2018.09.236.

Andrady, A.L., 2011. Microplastics in the marine environment. Marine Pollution Bulletin 62, 1596-1605. https://doi.org/10.1016/j.marpolbul .2011.05.030.

Andrady, A.L., Neal, M.A., 2009. Applications and societal benefits of plastics. Philosophical Transactions of the Royal Society B: Biological Sciences 364(1526), 1977-1984. https://doi.org/10.1098/rstb.2008.0304.

Awet, T.T., Kohl, Y., Meier, F., Straskraba, S., Grün, A.L., Ruf, T., Jost, C., Drexel, R., Tunc, E., Emmerling, C., 2018. Effects of polystyrene nanoparticles on the microbiota and functional diversity of enzymes in soil. Environmental Sciences Europe 30, 11. https://doi.org/10.1186/ s12302-018-0140-6.

Bläsing, M., Amelung, W., 2018. Plastics in soil: Analytical methods and possible sources. Science of the Total Environment 612, 422-435. https://doi.org/10.1016/j.scitotenv.2017.08.086.

Browne, M.A., Crump, P., Niven, S.J., Teuten, E., Tonkin, A., Galloway, T., Thompson, R., 2011. Accumulation of microplastics on shorelines worldwide: sources and sinks. Environmental Science \& Technology 45, 9175-9179. https://doi.org/10.1021/es201811s.

Carpenter, E.J., Smith, K.L., 1972. Plastics on the Sargasso Sea surface. Science 175(4027), 1240-1241. https://doi.org/10.1126/science. 175.4027.1240.

Carpenter, E.J., Anderson, S.J., Harvey, G.R., Miklas, H.P., Peck, B.B., 1972. Polystyrene spherules in coastal waters. Science 178(4062), 749-750. https://doi.org/10.1126/science.178.4062.74.9.

Choi, Y., 2020. Distribution of microplastics in soils of Seoul and Yeoju. Master Thesis. University of Seoul, Republic of Korea.

Choi, Y., Kim, Y.N., Yoon, J.H., Dickinson, N., Kim, K.H., 2020. Plastic contamination of forest, urban, and agricultural soils: a case study of Yeoju city in the Republic of Korea. Journal of Soils and Sediments. https://doi.org/10.1007/s11368-020-02759-0

Cole, M., Lindeque, P., Halsband, C., Galloway, T.S., 2011. Microplastics as contaminants in the marine environment: a review. Marine Pollution Bulletin 62(12), 2588-2597. https://doi.org/10.1016/j.marpolbul.2011.0 9.025 .

Corradini, F., Bartholomeus, H., Lwanga, E. H., Gertsen, H., Geissen, V., 2019. Predicting soil microplastic concentration using vis-NIR spectroscopy. Science of the Total Environment 650, 922-932. https://doi. org/10.1016/j.scitotenv.2018.09.101.

Cox, K.D., Covernton, G.A., Davies, H.L., Dower, J.F., Juanes, F., Dudas, S.E., 2019. Human consumption of microplastics. Environmental Science \& Technology 53(12), 7068-7074. https://doi.org/10.1021/acs. est.9b01517.

David, J., Steinmetz, Z., Kučeriik, J., Schaumann, G.E., 2018. Quantitative analysis of poly (ethylene terephthalate) microplastics in soil via thermogravimetry-mass spectrometry. Analytical Chemistry 90(15), 8793-8799. https://doi.org/10.1021/acs.analchem.8b00355.

da Costa, J.P., Santos, P.S., Duarte, A.C., Rocha-Santos, T., 2016. (Nano) plastics in the environment-sources, fates and effects. Science of the Total Environment 566, 15-26. https://doi.org/10.1016/j.scitotenv.201 6.05.041.

de Souza Machado, A.A., Lau, C.W., Kloas, W., Bergmann, J., Bachelier, J.B., Faltin, E., Becker, R., Gorlich, A.S., Rillig, M.C., 2019. Microplastics can change soil properties and affect plant performance. Environmental Science \& Technology 53(10), 6044-6052. https://doi.org/10.1021/acs. est.9b01339.

de Souza Machado, A.A., Lau, C.W., Till, J., Kloas, W., Lehmann, A., Becker, R., Rillig, M.C., 2018. Impacts of microplastics on the soil biophysical environment. Environmental Science \& Technology 52(17), 96569665. https://doi.org/10.1021/acs.est.8b02212.
Dümichen, E., Eisentraut, P., Bannick, C.G., Barthel, A.K., Senz, R., Braun, U., 2017. Fast identification of microplastics in complex environmental samples by a thermal degradation method. Chemosphere 174, 572-584. https://doi.org/10.1016/j.chemosphere.2017.02.010.

Eriksen, M., Mason, S., Wilson, S., Box, C., Zellers, A., Edwards, W., Farley H., Amato, S., 2013. Microplastic pollution in the surface waters of the Laurentian Great Lakes. Marine Pollution Bulletin 77(1-2), 177-182. https://doi.org/10.1016/j.marpolbul.2013.10.007.

Gajšt, T., 2016. Analysis of plastic residues in commercial compost. Bachelor Thesis, Univerza v Novi Gorici, Fakulteta za znanosti o okolju.

GESAMP, 2016. Sources, fate and effects of microplastics in the marine environment: part two of a global assessment. [In:] Kershaw, P.J., Rochman, C.M. (Eds.), IMO/FAO/UNESCO-IOC/UNIDO/WMO/IAEA/ UN/ UNEP/UNDP Joint Group of Experts on the Scientific Aspects of Marine Environmental Protection. Report and Study, GESAMP No. 93.

Geyer, R., 2020. Production, use, and fate of synthetic polymers. [In:] Lectcher, T.M. (Ed.), Plastic Waste and Recycling, London, Academic Press. 13-32.

Geyer, R., Jambeck, J.R., Law, K.L., 2017. Production, use, and fate of all plastics ever made. Science Advances 3(7), e1700782. https://doi. org/10.1126/sciadv.1700782.

Grbić, J., Helm, P., Athey, S., Rochman, C.M., 2020. Microplastics entering northwestern Lake Ontario are diverse and linked to urban sources. Water Research 174, 115623. https://doi.org/10.1016/ j.watres.2020.115623.

Guo, J.J., Huang, X.P., Xiang, L., Wang, Y.Z., Li, Y.W., Li, H., Cai, Q.Y., Mo, C.H., Wong, M.H., 2020. Source, migration and toxicology of microplastics in soil. Environment International 137, 105263. https://doi. org/10.1016/j.envint.2019.105263.

Hanvey, J.S., Lewis, P.J., Lavers, J.L., Crosbie, N.D., Pozo, K., Clarke, B.O., 2017. A review of analytical techniques for quantifying microplastics in sediments. Analytical Methods 9, 1369.

https://doi.org/0.1039/c6ay02707e.

He, D., Luo, Y., Lu, S., Liu, M., Song, Y., Lei, L., 2018. Microplastics in soils: analytical methods, pollution characteristics and ecological risks. TrAC Trends in Analytical Chemistry 109, 163-172. https://doi. org/10.1016/j.trac.2018.10.006.

Hodson, M.E., Duffus-Hodson, C.A., Clark, A., Prendergast-Miller, M.T., Thorpe, K.L., 2017. Plastic bag derived-microplastics as a vector for metal exposure in terrestrial invertebrates. Environmental Science \& Technology 51(8), 4714-4721. https://doi.org/10.1021/acs. est.7b00635.

Horton, A.A., Jürgens, M.D., Lahive, E., van Bodegom, P.M., Vijver, M.G., 2018. The influence of exposure and physiology on microplastic ingestion by the freshwater fish Rutilus rutilus (roach) in the River Thames, UK. Environmental Pollution 236, 188-194. https://doi. org/10.1016/j.envpol.2018.01.044.

Horton, A.A., Walton, A., Spurgeon, D.J., Lahive, E., Svendsen, C., 2017. Microplastics in freshwater and terrestrial environments: evaluating the current understanding to identify the knowledge gaps and future research priorities. Science of the Total Environment 586, 127-141. https://doi.org/0.1016/J.scitotenv.2017.01.190.

Huerta Lwanga, E. et al., 2017. Field evidence for transfer of plastic debris along a terrestrial food chain. Scientific Reports 7(1), 14071. https:// doi.org/10.1038/s41598-017-14588-2.

Hurley, R.R., Nizzetto, L., 2018. Fate and occurrence of micro (nano) plastics in soils: Knowledge gaps and possible risks. Current Opinion in Environmental Science \& Health 1, 6-11. https://doi.org/10.1016/ j.coesh.2017.10.006.

Imhof, H.K., Schmid, J., Niessner, R., Ivleva, N.P., Laforsch, C., 2012. A novel, highly efficient method for the separation and quantification of plastic particles in sediments of aquatic environments. Limnology and Oceanography: Methods 10(7), 524-537. https://doi.org/10.4319/ lom.2012.10.524. 
Jiang, X. et al., 2020. Assessment of Plastic Stocks and Flows in China: 1978-2017. Resources, Conservation and Recycling 161, 104969. https://doi.org/10.1016/j.resconrec.2020.104969.

Käppler, A., Fischer, M., Scholz-Böttcher, B. M., Oberbeckmann, S., Labrenz, M., Fischer, D., Eichhorn, K.J., Voit, B., 2018. Comparison of $\mu$-ATR-FTIR spectroscopy and py-GCMS as identification tools for microplastic particles and fibers isolated from river sediments. Analytical and Bioanalytical Chemistry 410(21), 5313-5327. https://doi. org/10.1007/s00216-018-1185-5.

Klein, M., Fischer, E.K., 2019. Microplastic abundance in atmospheric deposition within the Metropolitan area of Hamburg, Germany. Science of The Total Environment 685, 96-103. https://doi.org/10.1016/ j.scitotenv.2019.05.405.

Kim, H.Y., Um, N.I., Park, Y.S., Lee, Y.K., Kim, K.H., 2018. A study on the status and policy direction of collection and recycling of waste plastics. Journal of Korea Society of Waste Management 35(6), 471-480. https://doi.org/10.9786/kswm.2018.35.6.471.

Kim., K.J., Lee, H.S., Kim, Y.J., 2017. Distribution of microplastics on side of pavement in M city. Journal of Korean Society of Urban Environment, 17(4): 419-426.

Lahive, E., Walton, A., Horton, A.A., Spurgeon, D.J., Svendsen, C., 2019. Microplastic particles reduce reproduction in the terrestrial worm Enchytraeus crypticus in a soil exposure. Environmental Pollution 255, 113174. https://doi.org/10.1016/j.envpol.2019.113174.

Lebreton, L., Andrady, A., 2019. Future scenarios of global plastic waste generation and disposal. Palgrave Communications 5(1),1-11. https:// doi.org/10.1057/s41599-018-0212-7.

Lenz, R., Enders, K., Stedmon, C.A., Mackenzie, D.M., Nielsen, T.G., 2015. A critical assessment of visual identification of marine microplastic using Raman spectroscopy for analysis improvement. Marine Pollution Bulletin 100(1), 82-91. https://doi.org/10.1016/j.marpolbul.2015.0 9.026.

Liu, M. et al., 2018. Microplastic and mesoplastic pollution in farmland soils in suburbs of Shanghai, China. Environmental Pollution 242, 855-862. https://doi.org/10.1016/j.envpol.2018.07.051.

Lönnstedt, O.M., Eklöv, P., 2016. Environmentally relevant concentrations of microplastic particles influence larval fish ecology. Science 352(6290), 1213-1216. https://doi.org/10.1126/science.aad8828.

Mahon, A.M., O'Connell, B., Healy, M.G., O’Connor, I., Officer, R., Nash, R., Morrison, L., 2017. Microplastics in sewage sludge: effects of treatment. Environmental Science \& Technology 51(2), 810-818. https:// doi.org/10.1021/acs.est.6b04048.

Masura, J., Baker, J.E., Foster, G.D., Arthur, C., Herring, C., 2015. Laboratory methods for the analysis of microplastics in the marine environment: recommendations for quantifying synthetic particles in waters and sediments. NOAA Technical Memorandum NOS-OR\&R-48.

Mintenig, S.M., Int-Veen, I., Löder, M.G., Primpke, S., Gerdts, G., 2017. Identification of microplastic in effluents of waste water treatment plants using focal plane array-based micro-Fourier-transform infrared imaging. Water research 108, 365-372. https://doi.org/10.1016/ j.watres.2016.11.015.

Maaß, S., Daphi, D., Lehmann, A., Rillig, M.C., 2017. Transport of microplastics by two collembolan species. Environmental Pollution 225, 456-459. https://doi.org/10.1016/j.envpol.2017.03.009.

Nizzetto, L., Futter, M., Langaas, S., 2016. Are agricultural soils dumps for microplastics of urban origin?. Environmental Science \& Technology 50, 10777-10779. https://doi.org/10.1021/acs.est.6b04140.

Ng, E.L., Lwanga, E.H., Eldridge, S.M., Johnston, P., Hu, H.W., Geissen, V., Chen, D., 2018. An overview of microplastic and nanoplastic pollution in agroecosystems. Science of the Total Environment 627, 1377-1388. https://doi.org/10.1016/j.scitotenv.2018.01.341.

Nuelle, M.T., Dekiff, J.H., Remy, D., Fries, E., 2014. A new analytical approach for monitoring microplastics in marine sediments. Environmental Pollution 184, 161-169. https://doi.org/10.1016/ j.envpol.2013.07.027.
O’Connor, D., Pan, S., Shen, Z., Song, Y., Jin, Y., Wu, W.M., Hou, D., 2019. Microplastics undergo accelerated vertical migration in sand soil due to small size and wet-dry cycles. Environmental Pollution 249, 527-534. https://doi.org/10.1016/j.envpol.2019.03.092.

Plastics Europe, 2019. Plastics - The Facts 2019: An Analysis of European Plastics Production, Demand and Waste Data. Plastics Europe: Association of Plastics Manufacturers, Brussels.

Qi, R., Jones, D.L., Li, Z., Liu, Q., Yan, C., 2020. Behavior of microplastics and plastic film residues in the soil environment: A critical review. Science of the Total Environment 703, 134722. https://doi.org/10.1016/ j.scitotenv.2019.134722.

Ramos, L., Berenstein, G., Hughes, E.A., Zalts, A., Montserrat, J.M., 2015. Polyethylene film incorporation into the horticultural soil of small periurban production units in Argentina. Science of the Total Environment 523, 74-81. https://doi.org/10.1016/j.scitotenv.2015.03.142.

Rillig, M.C., 2012. Microplastic in terrestrial ecosystems and the soil? Environmental Science \& Technology 46, 6453-6454. https://doi. org/10.1021/es302011r.

Rillig, M.C., Ziersch, L., Hempel, S., 2017. Microplastic transport in soil by earthworms. Scientific reports 7(1), 1-6. https://doi.org/10.1038/ s41598-017-01594-7.

Rillig, M.C., 2018. Microplastic disguising as soil carbon storage. Environmental Science \& Technology 52, 6079-6080. https://doi.org/10.1021/ acs.est.8b02338.

Rillig, M.C., Lehmann, A., de Souza Machado, A.A., Yang, G., 2019. Microplastic effects on plants. New Phytologist 223(3), 1066-1070. https:// doi.org/10.1111/nph.15794.

Rodríguez-Seijo, A., Santos, B., da Silva, E.F., Cachada, A., Pereira, R., 2019. Low-density polyethylene microplastics as a source and carriers of agrochemicals to soil and earthworms. Environmental Chemistry 16(1), 8-17. https://doi.org/10.1071/EN18162.

Ryan, P.G., 2015. A brief history of marine litter research. [In:] Bergmann, M., Gutow, L., Klages, M. (Eds.), Marine Anthropogenic Litter. Springer, pp. 1-28.

Setälä, O., Norkko, J., Lehtiniemi, M., 2016. Feeding type affects microplastic ingestion in a coastal invertebrate community. Marine pollution bulletin 102(1), 95-101. https://doi.org/10.1016/j.marpolbul.2015.11.053.

Shah, A.A., Hasan, F., Hameed, A., Ahmed, S., 2008. Biological degradation of plastics: a comprehensive review. Biotechnology Advances 26(3), 246-265. https://doi.org/10.1016/j.biotechadv.2007.12.005.

Shan, J., Zhao, J., Zhang, Y., Liu, L., Wu, F., Wang, X., 2019. Simple and rapid detection of microplastics in seawater using hyperspectral imaging technology. Analytica Chimica Acta 1050, 161-168. https://doi. org/10.1016/j.aca.2018.11.008.

Shim, W.J., Hong, S.H., Eo, S.E., 2017. Identification methods in microplastic analysis: a review. Analytical Methods 9(9), 1384-1391. https://doi. org/10.1039/c6ay02558g.

Sommer, F., Dietze, V., Baum, A., Sauer, J., Gilge, S., Maschowski, C., Gieré, R., 2018. Tire abrasion as a major source of microplastics in the environment. Aerosol and Air Quality Research 18(8), 2014-2028. https://doi.org/10.4209/aaqr.2018.03.0099.

Statistics Korea, 2019. Statistics of manufacturing, import, and export of plastics in 2018.

Steinmetz, Z., Wollmann, C., Schaefer, M., Buchmann, C., David, J., Tröger, J., Muńoz, K, Fröer, O., Schaumann, G.E., 2016. Plastic mulching in agriculture. Trading short-term agronomic benefits for long-term soil degradation?. Science of the Total Environment 550, 690-705. https:// doi.org/10.1016/j.scitotenv.2016.01.153.

Sun, M. et al., 2018. Changes in tetracycline partitioning and bacteria/ phage-comediated ARGs in microplastic-contaminated greenhouse soil facilitated by sophorolipid. Journal of Hazardous Materials 345, 131-139. https://doi.org/10.1016/j.jhazmat.2017.11.036.

Thompson, R.C., Olsen, Y., Mitchell, R.P., Davis, A., Rowland, S.J., John, A.W., McGonigle, D., Russell, A.E., 2004. Lost at sea: where is all the plastic?. Science 304, 838. https://doi.org/10.1126/science.1094559. 
Thompson, R.C., Swan, S.H., Moore, C.J., Vom Saal, F.S., 2009. Our plastic age. Philosophical Transactions of the Royal Society B: Biological Sciences 364, 1973-1976. https://doi.org/10.1098/rstb.2009.0054.

Townsend, K.R., Lu, H.C., Sharley, D.J., Pettigrove, V., 2019. Associations between microplastic pollution and land use in urban wetland sediments. Environmental Science and Pollution Research 26, 2255122561. https://doi.org/10.1007/s11356-019-04885-w.

Wan, Y., Wu, C., Xue, Q., Hui, X., 2019. Effects of plastic contamination on water evaporation and desiccation cracking in soil. Science of the Total Environment 654, 576-582. https://doi.org/10.1016/j.scitotenv.2 018.11.123.

Wang, H.T., Ding, J., Xiong, C., Zhu, D., Li, G., Jia, X.Y., Zhu, Y.G., Xue, X.M., 2019a. Exposure to microplastics lowers arsenic accumulation and alters gut bacterial communities of earthworm Metaphire californica. Environmental Pollution 251, 110-116. https://doi.org/10.1016/ j.envpol.2019.04.054.

Wang, W., Ge, J., Yu, X., Li, H., 2020. Environmental fate and impacts of microplastics in soil ecosystems: progress and perspective. Science of the Total Environment 708, 134841. https://doi.org/10.1016/j.scitotenv.2019.134841.

Wang, J., Liu, X., Li, Y., Powell, T., Wang, X., Wang, G., Zhang, P., 2019b. Microplastics as contaminants in the soil environment: A mini-review. Science of The Total Environment 691, 848-857. https://doi. org/10.1016/j.scitotenv.2019.07.209.

Weithmann, N., Möller, J.N., Löder, M.G., Piehl, S., Laforsch, C., Freitag, R., 2018. Organic fertilizer as a vehicle for the entry of microplastic into the environment. Science Advances 4(4), eaap8060. https://doi. org/10.1126/sciadv.aap8060.
Wright, S.L., Ulke, J., Font, A., Chan, K.L.A., Kelly, F.J., 2020. Atmospheric microplastic deposition in an urban environment and an evaluation of transport. Environment International 136, 105411. https://doi. org/10.1016/j.envint.2019.105411.

Yang, X., Lwanga, E.H., Bemani, A., Gertsen, H., Salanki, T., Guo, X., Fu, H., Xue, S., Ritsema, C., Geissen, V., 2019. Biogenic transport of glyphosate in the presence of LDPE microplastics: A mesocosm experiment. Environmental Pollution 245, 829-835. https://doi.org/10.1016/ j.envpol.2018.11.044.

Zettler, E.R., Mincer, T.J., Amaral-Zettler, L.A., 2013. Life in the "plastisphere": microbial communities on plastic marine debris. Environmental Science \& Technology 47(13), 7137-7146. https://doi. org/10.1021/es401288x.

Zhang, S., Yang, X., Gertsen, H., Peters, P., Salánki, T., Geissen, V., 2018. A simple method for the extraction and identification of light density microplastics from soil. Science of the Total Environment 616. 10561065. https://doi.org/10.1016/j.scitotenv.2017.10.213.

Zhang, L., Xie, Y., Liu, J., Zhong, S., Qian, Y., Gao, P., 2020. An overlooked entry pathway of microplastics into agricultural soils from application of sludge-based fertilizers. Environmental Science \& Technology 54(7), 4248-4255. https://doi.org/10.1021/acs.est.9b07905.

Zhao, J., Liu, L., Zhang, Y., Wang, X., Wu, F., 2018. A novel way to rapidly monitor microplastics in soil by hyperspectral imaging technology and chemometrics. Environmental Pollution 238, 121-129. https:// doi.org/10.1016/j.envpol.2018.03.026. 